\title{
The comparison of the impact of arterial stiffness and central pressure on left ventricular geometry and diastolic function
}

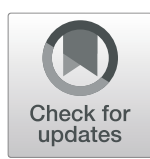

\author{
Hack-Lyoung Kim ${ }^{*}$ D, Woo-Hyun Lim, Jae-Bin Seo, Sang-Hyun Kim, Zoo-Hee Zo and Myung-A Kim
}

\begin{abstract}
Background: This study was performed to compare the associations of brachial-ankle pulse wave velocity (baPWV) and central blood pressure (CBP) measurements with left ventricular (LV) geometry and diastolic function.

Methods: A total of 77 subjects ( $64.5 \pm 10.8$ years, $67.5 \%$ females) without documented cardiovascular disease were prospectively recruited. All subjects underwent transthoracic echocardiography, baPWV and noninvasive measurement of CBP on the same day.

Results: In simple linear correlation analyses, neither baPWV nor CBP was associated with LV mass index or relative wall thickness ( $P>0.05$ for each). Although baPWV significantly correlated with septal $e^{\prime}$ velocity in simple linear correlation analyses $(r=0.258, P=0.025)$, the significance was lost after controlling for potential confounder $(P=0.881)$. In simple linear correlation analyses, central systolic blood pressure (CSBP) and central pulse pressure (CPP) significantly correlated with both septal $e^{\prime}$ velocity or E/e' $(P<0.05$ for each); however, neither central diastolic nor mean arterial pressures was associated with both septal e' velocity and E/e' $(P>$ 0.05 for each). After controlling for confounders, including age, sex and body mass index, CSBP correlated with septal $e^{\prime}$ velocity $(\beta=-0.258, P=0.025)$, but not with $E / e^{\prime}(P=0.074)$. CPP correlated with both septal $e^{\prime}$ velocity $(\beta=-0.300, P=0.014)$ and $E / e^{\prime}(\beta=0.428, P=0.002)$ in the same multivariable model.

Conclusions: In subjects without documented cardiovascular disease, CSBP and CPP may be more strongly associated with LV diastolic function than baPWV. Further studies with a larger sample size are needed to confirm our results.
\end{abstract}

Keywords: Arterial stiffness, Central blood pressure, Diastolic function, Left ventricle, Morphology

\section{Background}

Arteries stiffen with age, and cardiovascular diseases progress [1]. Information on arterial stiffness is clinically important in that it is associated with future cardiovascular events and mortality, independently of traditional risk factors [2-4]. Among several types of methods to measure arterial stiffness, pulse wave velocity (PWV) has been most widely used [5].

Central blood pressure (CBP) is the pressure in the ascending aorta, just outside of the left ventricle (LV). Based on the fact that major vital organs, such as the

\footnotetext{
*Correspondence: khl2876@gmail.com

Division of Cardiology, Department of Internal Medicine, Seoul National University College of Medicine, Boramae Medical Center, 5 Boramae-ro, Dongjak-gu, Seoul 07061, South Korea
}

heart and the brain, are more closely exposed to CBP than to brachial blood pressure (BrBP), emerging evidence has suggested that CBP is more predictive of future cardiovascular events than BrBP [6-8]. Also, CBP has been shown to be more closely associated with subclinical target organ damage, such as left ventricular (LV) hypertrophy and carotid atherosclerosis, than BrBP [7-9]. For these reasons, CBP measurement may be valuable in clinical practice. Although an invasive hemodynamic study is the gold standard for CBP measurement, it is not feasible in routine practice due to its invasiveness, cost and time. Fortunately, radial artery applanation tonometry, a recently developed noninvasive method, showed a strong correlation with invasively

(C) The Author(s). 2019 Open Access This article is distributed under the terms of the Creative Commons Attribution 4.0 International License (http://creativecommons.org/licenses/by/4.0/), which permits unrestricted use, distribution, and reproduction in any medium, provided you give appropriate credit to the original author(s) and the source, provide a link to the Creative Commons license, and indicate if changes were made. The Creative Commons Public Domain Dedication waiver (http://creativecommons.org/publicdomain/zero/1.0/) applies to the data made available in this article, unless otherwise stated. 
measured CBP (10) and is well-validated in many studies $[6,10]$.

It has been suggested that there was a close interaction between the LV and the aorta [11-15]. Arterial stiffening augments central systolic and pulse pressure (CSBP and CPP, respectively) leading to LV hypertrophy and LV diastolic dysfunction. Also, decreased central diastolic blood pressure (CDBP) in a stiffened aorta reduces coronary perfusion [15]. Although both arterial stiffness and CBP have a significant impact on the LV, most of the prior studies have only focused on arterial stiffness or CBP. It is of clinical value in patient management to find out what parameter affects the LV in the same subject. However, it has not been studied yet. Therefore, this study was performed to compare the associations of brachial-ankle pulse wave velocity (baPWV) and CBP measurements with LV geometry and diastolic function.

\section{Methods}

\section{Study population}

Between January and March 2018, consecutive adult subjects ( $\geq 18$ years) who visited Seoul Metropolitan Government Seoul National University Boramae Medical Center (Seoul, Korea) for cardiovascular examinations were prospectively enrolled in this study. Subjects were eligible if they had been never diagnosed with myocardial infarction, angina requiring revascularization, heart failure, peripheral arterial disease or stroke. Subjects with the following clinical conditions were also excluded: 1) unstable vital signs, 2) left ventricular ejection fraction $<50 \%, 3)$ valvular regurgitation or stenosis of mild degree and greater, 4) uncontrolled arrhythmia, and 5) ankle-brachial index $<0.9$ or $>1.4$. The study protocol was approved by the Institutional Review Board of Boramae Medical Center (Seoul, Korea). Written informed consent was obtained from each study subject.

\section{Data collection}

Body mass index (BMI) was calculated by dividing body weight $(\mathrm{kg})$ by the square of body height $(\mathrm{m})$. Hypertension was defined as systolic blood pressure $\geq 140 \mathrm{mmHg}$, diastolic blood pressure $\geq 90$ $\mathrm{mmHg}$, previous diagnosis of hypertension, or the use of antihypertensive medications. Diabetes mellitus, was defined as fasting glucose $\geq 126 \mathrm{mg} / \mathrm{dL}$, previous diagnosis of diabetes mellitus or the use of anti-diabetic medications. Dyslipidemia was defined as low-density lipoprotein cholesterol $\geq 160 \mathrm{mg} / \mathrm{dL}$, previous diagnosis of dyslipidemia, or the use of anti-dyslipidemic medications. Subjects were classified as smokers if they had smoked within the recent 12 months. All subjects underwent laboratory tests with venous blood taken in the morning after overnight fasting. White blood cell (WBC) count and hemoglobin concentration as well as serum levels of fasting glucose, total cholesterol, low-density lipoprotein (LDL) cholesterol, high-density lipoprotein (HDL) cholesterol, triglyceride, glycated hemoglobin (HbA1c) creatinine, and C-reactive protein were measured by an automated enzymatic procedure. Estimated glomerular filtration rate was calculated using the 4-component Modification of Diet in Renal Disease (MDRD) study equation incorporating age, race, sex, and serum creatinine level [16]. Data on cardiovascular medications, including calcium channel blocker, beta-blocker, angiotensin receptor blocker and statin, was also collected.

\section{baPWV measurement}

The volume-plethysmographic apparatus (VP-2000; Colin Co., Ltd., Komaki, Japan) was used for the measurement of baPWV. Each baPWV was measured in accordance with the manufacturer's instructions [17, 18]. Caffeine consumption, cigarette smoking, and alcohol consumption were prohibited before baPWV measurement on the study day. Each subject rested in the supine position in a quiet room for at least $5 \mathrm{~min}$ before the measurement. Electrocardiographic electrodes were applied to both wrists, phonocardiographic electrodes were placed on the edge of the sternum to detect heart sounds, and pneumatic cuffs were wrapped on both upper arms and ankles. PWV was calculated by dividing distance by transit time. The distance between measurement points of baPWV was estimated by subject height. Transit time was calculated from the start point of the brachial pulse wave to the start of the ankle pulse wave. The average value of left and right baPWV measurements was used for the study. The coefficient of variance for inter-observer reliability of baPWV was $5.1 \%$ in our laboratory [19].

\section{CBP measurement}

Immediately after baPWV measurement, CBP measurement was conducted using a commercially available radial artery applanation tonometry (HEM-9000AI; Omron Healthcare, Kyoto, Japan) [20]. Left radial artery pressure waveforms and right brachial blood pressure were simultaneously measured after resting in the sitting position for $\geq 5 \mathrm{~min}$. Then, we obtained the first and second peaks of peripheral systolic pressure (SBP1 and SBP2), respectively by calibrating the radial waveform with brachial systolic blood pressure. Finally, CBP was automatically calculated with a linear equation for SBP2 [21]. Pulse pressure (PP) was defined as the difference between systolic and diastolic blood pressures (SBP and DBP, respectively). 
Transthoracic echocardiography (TTE)

TTE was performed on the same day of CBP measurement. TTE was performed using commercially available devices (Sequoia; Siemens Medical Solutions, Mountain View, CA, USA or Vivid 7; GE Medical Systems, Milwaukie, WI, USA) according to the recommendations of the current guidelines [22, 23]. LV dimensions were measured on the parasternal short-axis view using Mmode echocardiography, and LV ejection fraction was measured on the apical 4- and 2-chamber views using the biplane Simpson's method. Relative wall thickness (RWT) was defined as 2 times posterior wall thickness divided by LV diastolic diameter, and the LV mass was calculated using a validated formula and indexed to the body surface area (LV mass index [LVMI]) [22]. All patients received pulsed wave Doppler examination at the tip of the mitral leaflets to measure peak early mitral inflow velocity during early diastole (E), late diastole (A), and deceleration time. Color-coded tissue Doppler imaging was performed on the apical 4-chamber view to calculate early velocity ( $\left.\mathrm{e}^{\prime}\right)$ at the septal mitral annulus. Left atrial volume index (LAVI) was measured with the biplane method on the apical 4- and 2-chamber views at ventricular end-systolic phases [23]. LV diastolic function was assessed using abnormal cutoff values (septal e ' $<7 \mathrm{~cm} / \mathrm{sec}$ and $\left.\mathrm{E} / \mathrm{e}^{\prime} \geq 15\right)$ recommended by the guideline [23]. Inter-observer agreements of septal $\mathrm{e}^{\prime}$ and $\mathrm{E} / \mathrm{e}^{\prime}$ were evaluated by Pearson's correlation among 50 subjects. The correlation coefficients were 0.96 and 0.92 for $\mathrm{e}^{\prime}$ and $\mathrm{E} / \mathrm{e}^{\prime}$, respectively, in our laboratory [24].

\section{Statistical analysis}

The continuous variables are presented as mean \pm SD, and categorical variables are expressed as percentages. Univariate associations between 2 parameters were assessed using simple linear regression analyses. Multivariable linear regression analysis was subsequently applied to examine independent relationships between individual parameters that had significant associations in univariate analyses. Age, sex, and BMI were adjusted during multivariable analyses. Scatter plots were used for the demonstration of linear correlations between 2 parameters. Correlations were compared using Meng's $Z$ test [25]. A $P$ value of $<0.05$ was considered statistically significant. All statistical analyses were conducted using SPSS 22.0 (IBM Corp., Armonk, NY, USA).

\section{Results}

\section{Clinical characteristics of the study subjects}

Clinical characteristics of the study subjects are presented in Table 1. Mean age was $64.5 \pm 10.8$ years, and $67.5 \%$ were female. The prevalence rates of hypertension, diabetes mellitus, and dyslipidemia were 48.1, 19.5, and $36.4 \%$, respectively. Approximately one-fourth of the
Table 1 Clinical characteristics of study subjects

\begin{tabular}{ll}
\hline Characteristic & Value $(n=77)$ \\
\hline Age, years & $64.5 \pm 10.8$ \\
Female sex, $n$ (\%) & $52(67.5)$ \\
Body mass index, $\mathrm{kg} / \mathrm{m}^{2}$ & $25.0 \pm 3.7$ \\
Cardiovascular risk factors, $n$ (\%) & \\
Hypertension & $37(48.1)$ \\
Diabetes mellitus & $15(19.5)$ \\
Dyslipidemia & $28(36.4)$ \\
Cigarette smoking & $20(26.0)$ \\
Laboratory findings & \\
White blood cell count, per microliter & $6,276 \pm 1,772$ \\
Hemoglobin, g/dL & $13.6 \pm 1.8$ \\
Total cholesterol, mg/dL & $174 \pm 37$ \\
LDL cholesterol, mg/dL & $102 \pm 34$ \\
HDL cholesterol, mg/dL & $52.9 \pm 12.0$ \\
Triglyceride, mg/dL & $121 \pm 76$ \\
HbA1c, \% & $5.97 \pm 0.98$ \\
Glomerular filtration rate, mL/min/1.73m ${ }^{2}$ & $88.2 \pm 20.5$ \\
Glomerular filtration rate $<60 \mathrm{~mL} / \mathrm{min}^{\prime} 1.73 \mathrm{~m}^{2}, n(\%)$ & $4(5.2)$ \\
C-reactive protein, mg/dL & $0.35 \pm 0.92$ \\
Concomitant medications, $n(\%)$ & \\
Calcium channel blocker & $10(13.0)$ \\
Beta-blocker & $13(16.9)$ \\
Angiotensin receptor blocker & $6(7.8)$ \\
Statin & $12(15.6)$ \\
\hline
\end{tabular}

patients $(26.0 \%)$ were current smokers. The mean value of WBC count, hemoglobin concentration, serum level of total cholesterol, LDL cholesterol, HDL cholesterol, triglyceride, HbA1c, glomerular filtration rate, and C-reactive protein were within the normal range. The proportion of subjects taking calcium channel blocker, betablocker, renin-angiotensin system blocker, and statin were 13.0, 16.9, 7.8, and 15.6\%, respectively. Results of TTE, baPWV, and CBP are shown in Table 2. All these parameters were within normal limits. The mean value of baPWV was $1,512 \pm 299 \mathrm{~cm} / \mathrm{s}$, and the mean values of central SBP and DBP were $137 \pm 19$ and $78.3 \pm 9.7$ $\mathrm{mmHg}$, respectively.

\section{Associations of arterial stiffness and CBP with LV geometry and diastolic function}

Univariable and multivariable analyses showing the associations of arterial stiffness and CBP with LV geometry and diastolic function are demonstrated in Table 3. The baPWV was not associated with LV geometric parameters, such as RWT or LVMI, in simple linear correlation analyses $\left(P>0.05\right.$ for each). It correlated with $\mathrm{e}^{\prime}$ velocity in simple correlation analysis $(r=-0.258, \quad P=0.025)$; 
Table 2 Results of echocardiography and measurements of arterial stiffness and blood pressure

\begin{tabular}{ll}
\hline Parameter & Value $(n=77)$ \\
\hline Echocardiography & \\
Left ventricular end-diastolic dimension, mm & $47.8 \pm 5.0$ \\
Left ventricular end-systolic dimension, $\mathrm{mm}$ & $29.8 \pm 5.8$ \\
Left ventricular ejection fraction, \% & $66.2 \pm 5.4$ \\
Relative wall thickness & $0.35 \pm 0.04$ \\
Left ventricular mass index, g/m ${ }^{2}$ & $82.9 \pm 21.2$ \\
E/A & $0.87 \pm 0.36$ \\
Deceleration time, ms & $219 \pm 50$ \\
Septal e' velocity, cm/s & $6.46 \pm 4.31$ \\
Septal E/e' & $11.4 \pm 4.4$ \\
Left atrial volume index, $\mathrm{mL} / \mathrm{m}^{2}$ & $33.1 \pm 11.0$ \\
Maximal velocity of tricuspid regurgitation flow, $\mathrm{m} / \mathrm{s}$ & $2.24 \pm 0.33$ \\
Brachial ankle pulse wave velocity, $\mathrm{cm} / \mathrm{s}$ & $1,512 \pm 299$ \\
Blood pressure measurements & \\
Brachial systolic blood pressure, $\mathrm{mmHg}$ & $131 \pm 18$ \\
Brachial diastolic blood pressure, $\mathrm{mmHg}$ & $76.1 \pm 9.9$ \\
Brachial mean arterial pressure, $\mathrm{mmHg}$ & $94.6 \pm 12.0$ \\
Brachial pulse pressure, mmHg & $55.6 \pm 12.5$ \\
Central systolic blood pressure, $\mathrm{mmHg}$ & $137 \pm 19$ \\
Central diastolic blood pressure, $\mathrm{mmHg}$ & $78.3 \pm 9.7$ \\
Central mean arterial pressure, $\mathrm{mmHg}$ & $98.0 \pm 11.2$ \\
Central pulse pressure, $\mathrm{mmHg}$ & $59.0 \pm 15.9$ \\
\hline & \\
&
\end{tabular}

however, the statistical significance disappeared in multivariable analysis $(P=0.881)$. CSBP correlated with $\mathrm{e}^{\prime}$ velocity $(r=-0.386, P=0.001)$ and E/e' $(r=0.314, P=$ $0.003)$, but not with RWT $(P=0.768)$ or LVMI $(P=0.869)$ in simple correlation analyses. In multivariable analysis after controlling for confounding effects of age, sex, and BMI, the statistical significance remained in the association between CSBP and $\mathrm{e}^{\prime}$ velocity $(r=-0.239, P=$ $0.025)$, but not in the association between CSBP and E/e' $(r=0.212, P=0.074)$. Neither CDBP nor CMAP was not associated with RWT, LVMI, e' velocity, or E/e' in simple correlation analyses $(P>0.05$ for each). CPP correlated with $\mathrm{e}^{\prime}$ velocity $(r=-0.490, P<0.001)$ and $\mathrm{E} / \mathrm{e}^{\prime} \quad(r=0.566$, $P<0.001)$, but not with RWT $(P=0.984)$ or LVMI $(P=$ $0.333)$ in simple correlation analyses. The statistical significances in the associations of CPP with $\mathrm{e}^{\prime}$ velocity $(\beta=-$ $0.300, P=0.014)$ and $E / \mathrm{e}^{\prime}(\beta=0.428, P=0.002)$ remained even after controlling for age, sex, and BMI in multivariable analyses. The linear correlations of baPWV and CPP with E/e' are demonstrated in Fig. 1. Brachial PP also showed a significant correlation with $\mathrm{E} / \mathrm{e}^{\prime}(r=0.454, P<0.001)$. The correlation coefficient was numerically smaller between brachial PP and E/e' than between CPP and E/e', although
Table 3 Associations of brachial-ankle pulse wave velocity and central blood pressure measurements with parameters of left ventricular geometry and diastolic function

\begin{tabular}{|c|c|c|c|c|}
\hline \multirow[t]{2}{*}{ Parameter } & \multicolumn{2}{|l|}{ Simple } & \multicolumn{2}{|c|}{ Multivariable $^{a}$} \\
\hline & $r$ & $P$ & $\beta$ & $P$ \\
\hline \multicolumn{5}{|l|}{ brachial-ankle pulse wave velocity } \\
\hline Relative wall thickness & 0.116 & 0.316 & - & - \\
\hline Left ventricular mass index & -0.071 & 0.547 & - & - \\
\hline$e^{\prime}$ velocity & -0.258 & 0.025 & -0.017 & 0.881 \\
\hline$E / e^{\prime}$ & 0.194 & 0.094 & - & - \\
\hline \multicolumn{5}{|l|}{ Central systolic blood pressure } \\
\hline Relative wall thickness & 0.034 & 0.768 & - & - \\
\hline Left ventricular mass index & 0.019 & 0.869 & - & - \\
\hline$e^{\prime}$ velocity & -0.386 & 0.001 & -0.239 & 0.025 \\
\hline$E / e^{\prime}$ & 0.341 & 0.003 & 0.212 & 0.074 \\
\hline \multicolumn{5}{|l|}{ Central diastolic blood pressure } \\
\hline Relative wall thickness & 0.063 & 0.588 & - & - \\
\hline Left ventricular mass index & -0.135 & 0.250 & - & - \\
\hline$e^{\prime}$ velocity & 0.054 & 0.640 & - & - \\
\hline$E / e^{\prime}$ & -0.161 & 0.101 & - & - \\
\hline \multicolumn{5}{|l|}{ Central mean arterial pressure } \\
\hline Relative wall thickness & 0.055 & 0.633 & - & - \\
\hline Left ventricular mass index & -0.069 & 0.558 & - & - \\
\hline$e^{\prime}$ velocity & -0.187 & 0.105 & - & - \\
\hline$E / e^{\prime}$ & 0.101 & 0.385 & - & - \\
\hline \multicolumn{5}{|l|}{ Central pulse pressure } \\
\hline Relative wall thickness & 0.002 & 0.984 & - & - \\
\hline Left ventricular mass index & 0.113 & 0.333 & - & - \\
\hline$e^{\prime}$ velocity & -0.490 & $<0.001$ & -0.300 & 0.014 \\
\hline$E / e^{\prime}$ & 0.566 & $<0.001$ & 0.428 & 0.002 \\
\hline
\end{tabular}

${ }^{a}$ Age, sex and body mass index are adjusted in this model

it was statistically insignificant $(P$ for difference $=0.111)$ (Fig. 2).

\section{Discussion}

The main findings of the present study are: 1) there were lack of associations of both baPWV and CBP with LV geometry; and 2) CSBP and CPP, but not baPWV, were associated with LV diastolic function. To the best of our knowledge, this is the first report showing more powerful association of CBP with LV diastolic function compared to arterial stiffness in the same subject.

\section{Association between CBP and LV diastolic function}

The association between CBP and LV diastolic function has been reported. Previously, our group has reported a significant association between invasively measured pulsatile pressure of the central aorta and LV diastolic parameters in 153 patients undergoing invasive coronary 

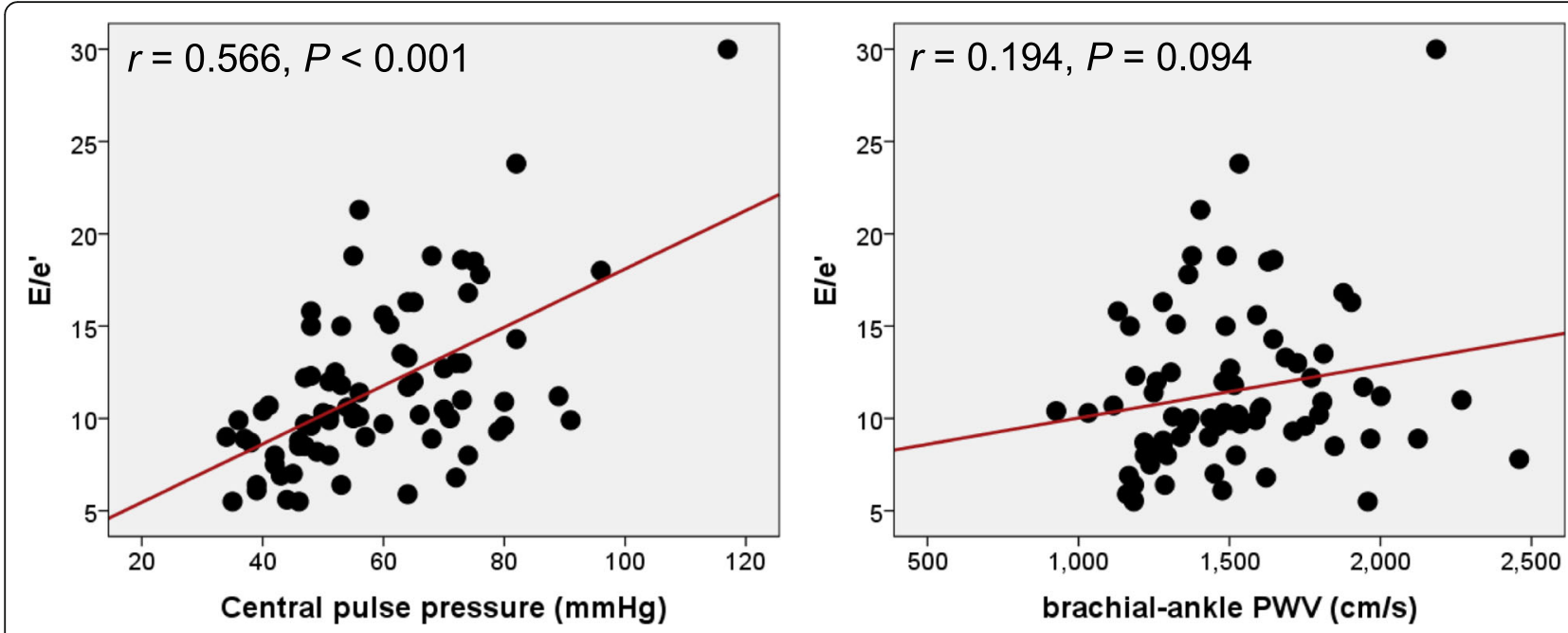

Fig. 1 The correlations of central pulse pressure and brachial-ankle PW with Ee/'. PW, pulse wave velocity

angiography [24]. Shim et al. [11] measured CBP using radial artery tonometry and showed that CPP amplification was independently associated with $\mathrm{e}^{\prime}$ velocity in women. A study of 1,233 community subjects demonstrated that CPP was associated with e' velocity and E/e ' ratio [13]. A recent longitudinal study of 607 subjects found that the increased $\mathrm{E} / \mathrm{e}^{\prime}$ ratio during the 4.7 years of follow-up was independently related to baseline CPP measured by radial artery tonometry in women [26]. In line with these studies, our study showed the association of CSBP and CPP with e' velocity, which supports the concept of ventricular-arterial relationship [15, 27, 28]. Increased CSBP represents increased LV afterload, which may slow LV relaxation. Additionally, widening of CPP with decreased CDBP reduces coronary perfusion during
LV diastole, causing further impairment of myocardial relaxation $[15,29]$.

\section{Lack of the association between baPWV and LV diastolic function}

There have been several studies reporting the association of arterial stiffness measured by baPWV with LV diastolic function. Analysis of 320 subjects with various abnormalities of cardiac structure and function have suggested that baPWV correlates with parameters of LV structure and function such as $\mathrm{LV}$ mass and mitral $\mathrm{e}^{\prime}$ velocity [30]. Wang et al. [31] reported that baPWV was independently and negatively associated with e' velocity in 42 hypertensive subjects. In apparently healthy 115 subjects, there was a significant correlation between baPWV and E/e' [32].
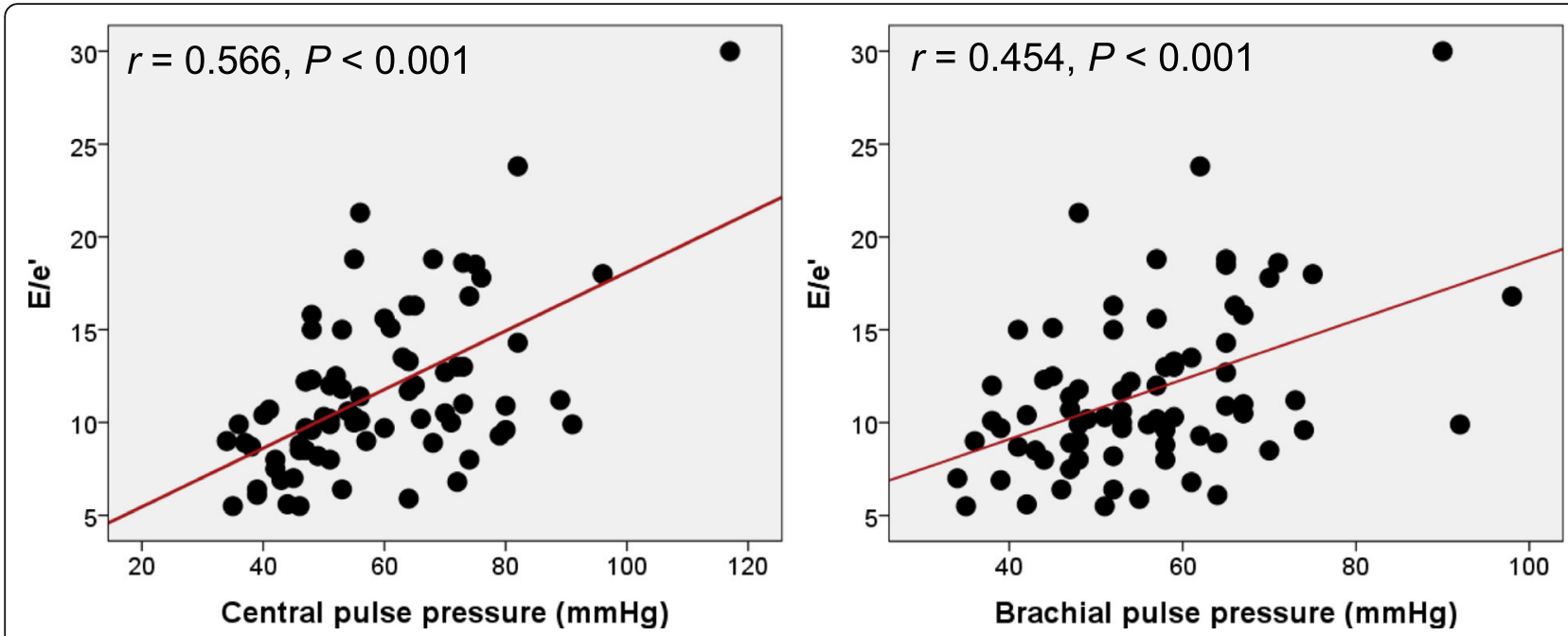

Fig. 2 The correlations of central and brachial pulse pressures with E/e 
Similarly, Kang et al. [33] investigated 2,095 community subjects and showed an independent association between baPWV and LV diastolic dysfunction. A previous study confirmed that baPWV was significantly associated with E/A ratio among healthy adults with normal LV ejection fraction [34]. On the contrary, the results of the present study showed that baPWV correlated with septal $\mathrm{e}^{\prime}$ velocity in univariable analyses; however, the significance of this correlation disappeared after controlling for age, sex, and BMI. It is thought that a different study population and a small sample size might be the main reason for the negative findings of our study. Further studies with a larger sample size are needed to determine the utility of baPWV and CBP in the prediction of LV diastolic function.

\section{Clinical implications}

A novel finding of our study is that CBP more affects LV diastolic function than arterial stiffness. This may suggest the importance of CBP as an indicator of LV diastolic dysfunction, which provides an additional insight in the interaction between LV and the arterial system. Given that LV diastolic dysfunction is associated with worse clinical outcomes [35, 36], CBP measurement may have more important implications for risk stratification than baPWV. CBP may be a good monitoring tool to assess LV diastolic dysfunction. In addition, revealing the degree of relationships between baPWV and CBP may be particularly important for treatment strategies. Targeting CBP may be more effective in reduction in patient risk than targeting baPWV. The potential targeted therapy should be explored to reduce CBP for the restoration of LV diastolic dysfunction or the prevention of heart failure. Moreover, there is lack of corroborative evidence that CBP reduction leads to the improvement in cardiovascular outcomes. Further prospective studies are needed to confirm this.

\section{Study limitations}

There are several limitations to this study. First, it is difficult to prove the causal relationship between CBP and LV diastolic function in this cross-sectional study. Secondly, there was the possibility that the small sample size of our study could not draw statistical significance in the relationships between baPWV and LV diastolic parameters, and between baPWV/CBP and LV geometry. For the same reason, some potential confounders, such as medications, could not be controlled during multivariable analyses. Also, although sex differences in ventricular-arterial relationships have been an issue $[11,26]$, sex-specific analysis could not be performed due to the small number of study subjects. Thirdly, baPWV was used as a measure of arterial stiffness in our study, instead of carotid-femoral PWV (cfPWV), a gold standard noninvasive measure of arterial stiffness [37]. However, baPWV has been shown to be strongly associated with cfPWV [38] and invasively measured aortic PWV [39]. In some studies, baPWV better correlated with LV mass and diastolic function than cfPWV [30]. Since baPWV includes both central and peripheral arterial stiffness, and cfPWV mainly reflects only central arterial stiffness, baPWV may be more representative of an arterial load of the LV than cfPWV [40]. Therefore, baPWV can be used as an indicator of arterial stiffness. Finally, our study subjects were middle-aged or older and without overt cardiovascular disease, so that our results cannot be generalized to other groups of subjects with different demographics and risk factors.

\section{Conclusions}

In middle-aged or older subjects without overt cardiovascular disease, CSBP and CPP were more strongly associated with LV diastolic function than baPWV. Measurement of CBP rather than baPWV may be more useful for the risk stratification and management of these age groups of subjects. Further studies with a larger sample size are warranted.

\section{Abbreviations \\ baPW: brachial-ankle pulse wave velocity; BMl: Body mass index BrBP: Brachial blood pressure; CBP: Central blood pressure; CDBP: Central diastolic blood pressure; cfPW: carotid-femoral pulse wave velocity; CPP: Central pulse pressure; CSBP: Central systolic blood pressure; DBP: Diastolic blood pressure; HDL: High-density lipoprotein; LAVI: Left atrial volume index; LDL: Low-density lipoprotein; LV: Left ventricle; LVMI: Left ventricular mass index; MDRD: Modification of Diet in Renal Disease; PP: Pulse pressure; PWV: Pulse wave velocity; RWT: Relative wall thickness; SBP: Systolic blood pressure; TTE: Transthoracic echocardiography; WBC: White blood cell}

\section{Acknowledgements}

Not applicable.

\section{Authors' contributions}

H-LK contributed to conceptualization, design, data analysis, drafting and preparation of the manuscript. W-HL, J-BS, S-HK, J-HZ and M-AK contributed to data gathering and data management. All authors read and approved the final manuscript.

\section{Funding}

This study was supported by a research grant from the Korean Society of Hypertension.

\section{Availability of data and materials}

The datasets used and/or analyzed during the current study are available from the corresponding author on reasonable request.

Ethics approval and consent to participate

The study protocol was approved by the Institutional Review Board of Boramae Medical Center (Seoul, Korea). Written informed consent was obtained from each study subject.

Consent for publication

Not applicable. 


\section{Competing interests}

The authors declare that they have no competing interests.

Received: 30 April 2019 Accepted: 12 July 2019 Published online: 01 September 2019

\section{References}

1. Lee HY, Oh BH. Aging and arterial stiffness. Circ J. 2010;74:2257-62.

2. Ichikawa K, Sakuragi S, Nishihara T, Tsuji M, Mori A, Yokohama F, et al. Influence of arterial stiffness on cardiovascular outcome in patients without high blood pressure. Heart. 2018;104:318-23.

3. Mitchell GF, Hwang SJ, Vasan RS, Larson MG, Pencina MJ, Hamburg NM, et al. Arterial stiffness and cardiovascular events: the Framingham heart study. Circulation. 2010;121:505-11.

4. Vlachopoulos C, Aznaouridis K, Stefanadis C. Prediction of cardiovascular events and all-cause mortality with arterial stiffness: a systematic review and meta-analysis. J Am Coll Cardiol. 2010;55:1318-27.

5. Cavalcante JL, Lima JA, Redheuil A, Al-Mallah MH. Aortic stiffness: current understanding and future directions. J Am Coll Cardiol. 2011;57:1511-22.

6. McEniery CM, Cockcroft JR, Roman MJ, Franklin SS, Wilkinson IB. Central blood pressure: current evidence and clinical importance. Eur Heart J. 2014:35:1719-25.

7. Wang KL, Cheng HM, Chuang SY, Spurgeon HA, Ting CT, Lakatta EG, et al. Central or peripheral systolic or pulse pressure: which best relates to target organs and future mortality? J Hypertens. 2009;27:461-7.

8. Roman MJ, Devereux RB, Kizer JR, Lee ET, Galloway JM, Ali T, et al. Central pressure more strongly relates to vascular disease and outcome than does brachial pressure: the strong heart study. Hypertension. 2007;50:197-203.

9. Weber T, Wassertheurer S, Schmidt-Trucksass A, Rodilla E, Ablasser C, Jankowski P, et al. Relationship between 24-hour ambulatory central systolic blood pressure and left ventricular mass: a prospective multicenter study. Hypertension. 2017;70:1157-64.

10. Nelson MR, Stepanek J, Cevette M, Covalciuc M, Hurst RT, Tajik AJ. Noninvasive measurement of central vascular pressures with arterial tonometry: clinical revival of the pulse pressure waveform? Mayo Clin Proc. 2010;85:460-72.

11. Shim CY, Park S, Choi D, Yang WI, Cho IJ, Choi EY, et al. Sex differences in central hemodynamics and their relationship to left ventricular diastolic function. J Am Coll Cardiol. 2011;57:1226-33.

12. Kim KJ, Kim HL, Kim MJ, Kim CH, Lim WH, Seo JB, et al. Gender difference in the association between aortic pulse pressure and left ventricular filling pressure in the elderly: an invasive hemodynamic study. J Card Fail. 2017:23:224-30

13. Cauwenberghs N, Knez J, Tikhonoff V, D'Hooge J, Kloch-Badelek M, Thijs L, et al. Doppler indexes of left ventricular systolic and diastolic function in relation to the arterial stiffness in a general population. J Hypertens. 2016:34:762-71.

14. Kaess BM, Rong J, Larson MG, Hamburg NM, Vita JA, Cheng S, et al. Relations of central hemodynamics and aortic stiffness with left ventricular structure and function: the Framingham heart study. J Am Heart Assoc. 2016:5:e002693.

15. Mottram PM, Haluska BA, Leano R, Carlier S, Case C, Marwick TH. Relation of arterial stiffness to diastolic dysfunction in hypertensive heart disease. Heart. 2005;91:1551-6.

16. Levey AS, Bosch JP, Lewis JB, Greene T, Rogers N, Roth D. A more accurate method to estimate glomerular filtration rate from serum creatinine: a new prediction equation. Modification of diet in renal disease study group. Ann Int Med. 1999:130:461-70.

17. Hwang IC, Jin KN, Kim HL, Kim YN, Im MS, Lim WH, et al. Additional prognostic value of brachial-ankle pulse wave velocity to coronary computed tomography angiography in patients with suspected coronary artery disease. Atherosclerosis. 2018;268:127-37.

18. Jang K, Kim HL, Park M, Oh S, Oh SW, Lim WH, et al. Additional value of brachial-ankle pulse wave velocity to single-photon emission computed tomography in the diagnosis of coronary artery disease. J Atheroscler Thromb. 2017;24:1249-57.

19. Lee HS, Kim HL, Kim H, Hwang D, Choi HM, Oh SW, et al. Incremental prognostic value of brachial-ankle pulse wave velocity to single-photon emission computed tomography in patients with suspected coronary artery disease. J Atheroscler Thromb. 2015;22:1040-50.
20. Takazawa K, Kobayashi H, Shindo N, Tanaka N, Yamashina A. Relationship between radial and central arterial pulse wave and evaluation of central aortic pressure using the radial arterial pulse wave. Hypertens Res. 2007;30:219-28.

21. Sharman JE, Lim R, Qasem AM, Coombes JS, Burgess MI, Franco J, et al. Validation of a generalized transfer function to noninvasively derive central blood pressure during exercise. Hypertension. 2006;47:1203-8.

22. Lang RM, Badano LP, Mor-Avi V, Afilalo J, Armstrong A, Ernande L, et al. Recommendations for cardiac chamber quantification by echocardiography in adults: an update from the American Society of Echocardiography and the European Association of Cardiovascular Imaging. J Am Soc Echocardiogr. 2015;28:1-39. e14.

23. Nagueh SF, Smiseth OA, Appleton CP, Byrd BF 3rd, Dokainish H, Edvardsen $T$, et al. Recommendations for the evaluation of left ventricular diastolic function by echocardiography: an update from the American Society of Echocardiography and the European Association of Cardiovascular Imaging. Eur Heart J Cardiovasc Imaging. 2016;17:1321-60.

24. Kim HL, Seo JB, Chung WY, Kim SH, Kim MA, Zo JH. Association between invasively measured central aortic pressure and left ventricular diastolic function in patients undergoing coronary angiography. Am J Hypertens. 2015;28:393-400.

25. Sandoo A, Chanchlani N, Hodson J, Smith JP, Douglas KM, Kitas GD. The relationship between cardiovascular disease risk prediction scores and vascular function and morphology in rheumatoid arthritis. Clin Exp Rheumatol. 2014;32:914-21.

26. Cauwenberghs N, Knez J, D'Hooge J, Thijs L, Yang WY, Wei FF, et al. Longitudinal changes in LV structure and diastolic function in relation to arterial properties in general population. JACC Cardiovasc Imaging. 2017;10:1307-16.

27. Weber T, Chirinos JA. Pulsatile arterial haemodynamics in heart failure. Eur Heart J. 2018;39:3847-54

28. Kim D, Shim CY, Hong GR, Park S, Cho I, Chang HJ, et al. Differences in left ventricular functional adaptation to arterial stiffness and neurohormonal activation in patients with hypertension: a study with two-dimensional layer-specific speckle tracking echocardiography. Clin Hypertens. 2017;23:21.

29. Watanabe H, Ohtsuka S, Kakihana M, Sugishita Y. Coronary circulation in dogs with an experimental decrease in aortic compliance. J Am Coll Cardiol. 1993;21:1497-506

30. Yu WC, Chuang SY, Lin YP, Chen CH. Brachial-ankle vs carotid-femoral pulse wave velocity as a determinant of cardiovascular structure and function. J Hu Hypertens. 2008;22:24-31.

31. Wang CP, Hung WC, Yu TH, Hsu HL, Chen YH, Chiu CA, et al. Brachialankle pulse wave velocity as an early indicator of left ventricular diastolic function among hypertensive subjects. Clin Exp Hypertens. 2009;31:31-43.

32. Kim HL, Im MS, Seo JB, Chung WY, Kim SH, Kim MA, et al. The association between arterial stiffness and left ventricular filling pressure in an apparently healthy Korean population. Cardiovasc Ultrasound. 2013;11:2.

33. Kang S, Fan HM, Li J, Fan LY, Miao AY, Bao Y, et al. Relationship of arterial stiffness and early mild diastolic heart failure in general middle and aged population. Eur Heart J. 2010;31:2799-807.

34. Xu L, Jiang CQ, Lam TH, Yue XJ, Lin JM, Cheng KK, et al. Arterial stiffness and left-ventricular diastolic dysfunction: Guangzhou biobank cohort studyCVD. J Hu Hypertens. 2011;25:152-8.

35. Bella JN, Palmieri V, Roman MJ, Liu JE, Welty TK, Lee ET, et al. Mitral ratio of peak early to late diastolic filling velocity as a predictor of mortality in middle-aged and elderly adults: the strong heart study. Circulation. 2002;105:1928-33.

36. Pritchett AM, Mahoney DW, Jacobsen SJ, Rodeheffer RJ, Karon BL, Redfield MM. Diastolic dysfunction and left atrial volume: a population-based study. J Am Coll Cardiol. 2005:45:87-92.

37. Laurent S, Cockcroft J, Van Bortel L, Boutouyrie P, Giannattasio C, Hayoz D, et al. Expert consensus document on arterial stiffness: methodological issues and clinical applications. Eur Heart J. 2006;27:2588-605.

38. Tanaka H, Munakata M, Kawano $Y$, Ohishi M, Shoji T, Sugawara J, et al. Comparison between carotid-femoral and brachial-ankle pulse wave velocity as measures of arterial stiffness. J Hypertens. 2009;27:2022-7. 
39. Yamashina A, Tomiyama H, Takeda K, Tsuda H, Arai T, Hirose K, et al Validity, reproducibility, and clinical significance of noninvasive brachial-ankle pulse wave velocity measurement. Hypertens Res. 2002:25:359-64.

40. Park KH, Park WJ, Kim MK, Jung JH, Choi S, Cho JR, et al. Noninvasive brachial-ankle pulse wave velocity in hypertensive patients with left ventricular hypertrophy. Am J Hypertens. 2010;23:269-74.

\section{Publisher's Note}

Springer Nature remains neutral with regard to jurisdictional claims in published maps and institutional affiliations.

Ready to submit your research? Choose BMC and benefit from:

- fast, convenient online submission

- thorough peer review by experienced researchers in your field

- rapid publication on acceptance

- support for research data, including large and complex data types

- gold Open Access which fosters wider collaboration and increased citations

- maximum visibility for your research: over $100 \mathrm{M}$ website views per year

At $\mathrm{BMC}$, research is always in progress.

Learn more biomedcentral.com/submissions 